\title{
LAGS IN BEHAVIORAL CHANGE: A POPULATION BASED COMPARISON OF CARDIOVASCULAR RISK BEHAVIOR IN POLAND AND SWEDEN
}

\author{
Per Andersson ${ }^{1}$, Rickard L. Sjöberg ${ }^{2}$, Marzena Krysa ${ }^{3}$, Władysław Sidorowicz ${ }^{3}$, John Öhrvik ${ }^{2}$, Jerzy Leppert ${ }^{2}$ \\ ${ }^{1}$ Department of Caring and Public Health Science, Mälardalen University, S-72123 Västerås, Sweden \\ ${ }^{2}$ Centre of Clinical Research, Uppsala University, Central Hospital, Västerås, Sweden \\ ${ }^{3}$ Health and Welfare Division of the Municipality of Wroclaw City, Wroclaw, Poland
}

\begin{abstract}
SUMMARY
One thousand and twenty Polish men and women and 1,011 Swedish men and women aged 50 and recruited through primary health care took part in a survey relating to their knowledge of health-related behaviour, attitudes to health-related behaviour and self-reported risk behaviour. The results reveal that Poles know as much about cardiovascular risk factors as Swedes, but that Swedes feel that it is more important to change their dietary habits and to influence factors in the working environment to avoid the risk of developing CVD than did Poles. Swedes also displayed less risk behaviour than Poles and more Swedes than Poles had successfully stopped smoking. These findings suggest that differences in stages of health-related behavior that have previously been observed at an individual level may sometimes also be discerned at a national level.
\end{abstract}

Key words: knowledge of risk factors, CVD, population-based study, stage-of-change model

Address for correspondence: Per Andersson, Department of Caring and Public Health Science, Mälardalen University, S-72123 Västerås, Sweden. E-mail: per.andersson@mdh.se

\section{INTRODUCTION}

One key assumption on which a great deal of current health promotion is based is that, if individuals realise that their behaviour may put them at risk of disease, a change of attitude towards the risky behaviour, as well as a change in behaviour, will follow. As a consequence, societal attempts to improve morbidity and mortality rates for common conditions such as cardiovascular disease often take the form of general information campaigns relating to behavioural risk factors for these kinds of conditions. However, at least one recent study performed in the former USSR suggests that the correlation between knowledge of behavioural risk factors and healthy behaviour and some areas of health promotion is actually relatively weak in some countries (1). One possible explanation for such findings could be that there is a national time lag in the effects of health campaigns similar to those that occur during the process of health-related change in individual patients (2-4).

One possible way of investigating the hypothesis that populations in different countries could be meaningfully described as being in different stages of change would be to make a comparison between a post-Communist country such as Poland and a stable, "old" European democracy such as Sweden.

Several observations suggest that educational level and health are positively related in post-Communist Eastern Europe (5) and that there has been an increase in health-related variables such as life expectancy following the transition from Communism to democracy. However, it is surprising to find that observations suggest that changes in cardiovascular risk behaviour in Poland during the early 1990s were marginal (6).
In Sweden, health campaigns designed to increase public knowledge and the awareness of risk factors for cardiovascular disease (CVD) have been common for many years and several interventions have been tested to improve health behaviour (7-9). The Polish population, on the other hand, has recently experienced some of its first public health campaigns in this area $(10,11)$. In the mid 1990s, representatives from the Swedish county of Västmanland introduced and supported similar screening programs for CVD risk factors and behaviours in Västmanland and Wroclaw, Poland (12, 13).

The purpose of the present study was therefore to investigate whether knowledge about cardiovascular risk factors, motivation to control risk-related behavior and actual risk behaviour differed between Poland and Sweden on the basis of information obtained during this screening programme.

\section{MATERIAL AND METHODS}

\section{Study Populations and Data Collection}

This investigation was performed according to a specific screening programme designed to study potential CVD risk factors in 50-year-olds in the city of Wroclaw, Poland, and in the County of Västmanland, Sweden (12). The Polish data were collected between October 2000 and January 2001 and the Swedish data were collected between May 1997 and April 1998.

Wroclaw has a population of 640,000 and is situated in the region of Lower Silesia, located in south-western Poland. The region of Wroclaw is highly industrialised and Wroclaw is one 
of the largest university centres in the country. The County of Västmanland, Sweden, with a population of about 260,000, is industrialised and does not differ in terms of demographic factors from other counties in the central part of Sweden (13).

In the region of Wroclaw, there are 89 Health Care Centres (HCC) of different sizes and with different management set-ups. The screening procedure based on a model previously developed in the County of Västmanland was organized by the Wroclaw Health Department and, during this study, 10 HCCs were considered for participation in the screening procedure. In 2000, these 10 HCCs provided services to 2,205 men and women aged 50 . All of them were sent an invitation to participate in the screening procedure and 1,043 (47\%; 417 men and 622 women) agreed to participate. The study questionnaires were completed by 1,020 individuals ( $46 \%$; 406 men and 614 women). In the same way in 1981, 50-year-old individuals living in the County of Västmanland in Sweden were invited to participate and 1,129 (57\%) of them took part in the screening procedure at 34 of a total of 36 HCCs. Finally, 1,011 individuals (1,011/1,981; 51\%) (554 women and 457 men) completed the questionnaire.

\section{Questionnaires}

A questionnaire similar to that used in an earlier study and containing items pertaining to background variables (e.g. gender and level of education) and items relating to knowledge of important risk factors for CVD was used (14). The questions about knowledge were divided into two main groups; firstly, questions were asked about whether behaviors (e.g. smoking, exercise, diet, alcohol, stress, overweight) were considered by the participant to be very important, important, unimportant in reducing the risk of developing cardiovascular disease and, secondly, questions were asked (18 items) about whether the participant felt that a number of factors would increase or reduce the risk of developing cardiovascular disease (yes, no or don't know). The Polish questionnaire was adapted from translations of the questionnaires used in the Swedish study (12).

Smoking behaviour was classified into one of three categories (never smoked, ex-smokers, smokers). Exercise was assessed on a self-reported five-point scale (daily exercise, exercise 3-4 times a week, exercise 1-2 times a week, exercise 1-2 times a month, exercise never). Education was divided into two categories: low education level (compulsory school and completion of sixth-form college) and high education level (university studies).

In Sweden, 12 years of education comprises nine years of compulsory primary schooling and three years of secondary schooling (sixth-form college). After this, the next level is university studies. Twelve years is thus a natural cut-off point when the nature of the Swedish educational system is considered. For demographic data, see Table 1. The Swedish study was approved by the regional ethics committee (Uppsala University, Sweden). The head of the health authorities in the City of Wroclaw conducted the Polish part.

\section{Non-participants}

In the Swedish annual screening programme for CVD, an analysis of non-participants was carried out three years before this study (both 40 and 50 years of age). Random samples of eight HCCs with 112 non-participants were involved in the analysis.
A questionnaire that included questions about demographic data, smoking and exercise habits, heredity for CVD and reasons for not participating in the screening was distributed to this group. The non-participants were more often men, smokers and/or with a low education level. No systematic differences between non-participants and participants were found for other variables (13).

\section{Statistical Analyses}

Multiple logistic regression was used for comparisons of dichotomy responses between groups from different countries (Poland $=1$, Sweden=0), gender $($ men=1, woman=0), level of education (low education $=1$, high education $=0$ ). Ordinal logistic regression was used for analyses of ordinal responses (smoking: $0=$ never smoked, $1=$ ex-smokers, $2=$ smokers; exercise: $0=$ daily, 1=3-4 times/week, 2=1-2 times/week, 3=1-2 times/month, $4=$ never). The level of statistical significance was $p \leq 0.05$, two-sided.

\section{RESULTS}

Table 1 summarises the study sample. There were a total of 2,031 men and women in the survey, with 1,020 from Poland and 1,011 from Sweden. There were more women than men in both samples and more highly-educated participants in the Polish sample than in the Swedish sample. (Table 1)

Table 1. Demographic data

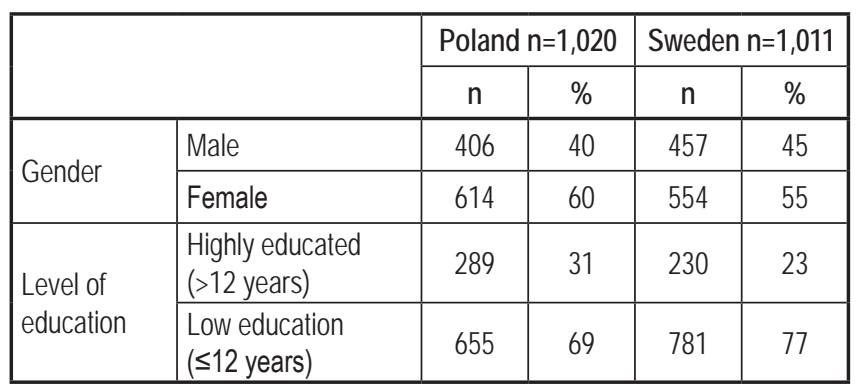

\section{Knowledge of Factors Influencing the Risk of Developing Cardiovascular Disease Comparison between Sweden and Poland}

The Polish participants (adjusted for gender and level of education) stressed significantly $(\mathrm{p}<0.05)$ more than the Swedish participants that smoking, a stressful life, high blood pressure, high levels of cholesterol in food, high blood cholesterol, high alcohol intake, saturated fat in food, high age, diabetes, sugary food and unemployment were factors which increased the risk of developing CVD. On the other hand, the Swedish participants reported to a significantly greater extent that heredity increased the risk and plenty of fibre in food reduced the risk $(\mathrm{p}<0.05)$ (Table 2).

Willingness to Change Lifestyle Habits that Potentially Inhibit
the Onset of CVD Comparison between Sweden and Poland
Fifty-four per cent of Swedish participants and $23 \%$ of Poli-
sh participants mentioned that it was very important to change
dietary habits in order to inhibit the onset of CVD (OR 0.25 , CI
$0.2-0.3$; $<<0.001$ ). The Polish participants reported to a signifi- 
Table 2. Logistic regression of country, Sweden as a reference vs Poland, as an explanation of differences to judge which factor increases/reduces the risk of developing CVD

\begin{tabular}{|l|c|c|}
\hline Factor & OR (95\% CI) & p \\
\hline Smoking increases the risk & $2.1(1.2-3.5)$ & 0.004 \\
\hline Stressful life increases the risk & $3.8(2.2-6.3)$ & $<0.001$ \\
\hline Overweight increases the risk & $1.3(0.8-2.3)$ & $\mathrm{nS}$ \\
\hline Fatty food increases the risk & $0.6(0.4-1.0)$ & $\mathrm{nS}$ \\
\hline High blood pressure increases the risk & $4.2(3.0-6.0)$ & $<0.001$ \\
\hline Exercise reduces the risk & $1.7(1.2-2.4)$ & 0.005 \\
\hline A lot of cholesterol in food increases the risk & $3.2(2.3-4.4)$ & $<0.001$ \\
\hline High blood cholesterol increases the risk & $2.5(1.8-3.5)$ & $<0.001$ \\
\hline High alcohol intake increases the risk & $3.9(2.9-5.1)$ & $<0.001$ \\
\hline Saturated fat in food increases the risk & $1.8(1.5-2.2)$ & $<0.001$ \\
\hline High age increases the risk & $2.5(2.0-3.0)$ & $<0.001$ \\
\hline Diabetes increases the risk & $5.2(4.3-6.3)$ & $<0.001$ \\
\hline Sugary food increases the risk & $3.1(2.6-3.8)$ & $<0.001$ \\
\hline Heredity increases the risk & $0.5(0.4-0.6)$ & $<0.001$ \\
\hline A lot of fibre in food reduces the risk & $0.2(0.1-0.2)$ & $<0.001$ \\
\hline High coffee intake increases the risk & $7.6(6.2-9.3)$ & $<0.001$ \\
\hline Unemployment increases the risk & $24.9(19.1-32.6)$ & $<0.001$ \\
\hline Being male increases the risk & $1.0(0.8-1.2)$ & $\mathrm{ns}$ \\
\hline
\end{tabular}

cantly greater extent than the Swedish participants that it was very important to influence stress to avoid the risk of CVD (72\% versus $60 \%$ ) (OR 1.7, CI 1.4-2.1; $<<0.001$ ). Thirty-two per cent of the Swedish participants and $27 \%$ of the Polish participants reported that it was very important to change the working environment (OR 0.8, 0.6-1.0; $\mathrm{p}=0.033$ ). These differences between Sweden and Poland existed even when the data were adjusted for gender and level of education; see Table 3. Men reported that diet, stressful life, alcohol habits and working environment were less important than women. These proportional differences were significant even after adjustments had been made for country and level of education. People with a high level of education tended to stressed the importance of changing dietary habits to a higher degree than people with a low education level and people with low level of education reported the importance of changing alcohol habits, adjusted for country and gender.

\section{Prevalence of Behavior-related Risk Factors among Polish} and Swedish Participants

As far as smoking was concerned, behavioural change was most common among the Swedes (Table 4). Poles were smokers to a significantly greater extent than Swedes [33\% vs 25\%; OR 1.7 (CI 1.25-2) $\mathrm{p}<0.001]$ after adjustments were made for gender and level of education. Furthermore, $39 \%$ (men $42 \%$ vs women $36 \%$ ) of the Swedes had previously been smokers, whereas only $23 \%$ of the Poles were ex-smokers (men 31\% vs women 18\%). These proportional differences were significant even after adjustments were made for gender and level of education (OR 0.4, CI 0.3-0.5; $\mathrm{p}<0.001)$. Among Polish participants who had never smoked, 33\% were men and 51\% women, while among Swedes $33 \%$ were men and $39 \%$ women.

As can be seen in Table 4, 16\% of the Swedes exercised once a month or less, whereas the corresponding figure for the Poles was $32 \%$. These differences were also significant after being adjusted for gender and level of education in ordinal logistic regression (OR 0.2 CI 0.04-0.35).

Table 4. Distribution of smoking and exercise habits among Polish and Swedish participants

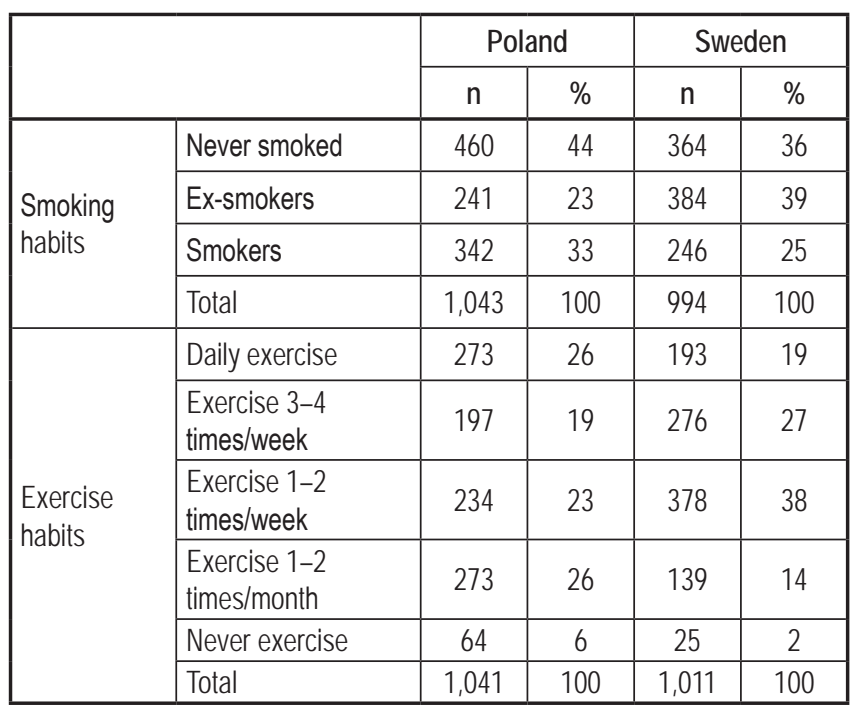

\section{DISCUSSION}

The results of the present study show that, even when compared to Swedes, Poles had a high level of knowledge about the risk factors for developing CVD. However, Swedes felt that it was far more important than Poles to change their dietary habits and influence factors in the working environment to avoid the risk of developing CVD. Furthermore, Swedes displayed less risk beha-

Table 3. Differences between country, gender and level of education related to the importance of changing habits that could potentially reduce the risk of CVD expressed as odds ratios with $95 \% \mathrm{CI}$

\begin{tabular}{|l|c|c|c|c|}
\hline & $\begin{array}{c}\text { Diet } \\
\text { OR }(95 \% \mathrm{Cl})\end{array}$ & $\begin{array}{c}\text { Stress } \\
\text { OR }(95 \% \mathrm{Cl})\end{array}$ & $\begin{array}{c}\text { Working environment } \\
\text { OR }(95 \% \mathrm{Cl})\end{array}$ & $\begin{array}{c}\text { Alcohol } \\
\text { OR }(95 \% \mathrm{Cl})\end{array}$ \\
\hline Crude Country & $0.25(0.2-0.3)$ & $1.7(1.4-2.1)$ & $0.8(0.6-1.0)$ & $1.1(0.9-1.4)$ \\
(reference: Sweden) & $\mathrm{p}<0.001$ & $\mathrm{p}<0.001$ & $\mathrm{n}=0.03$ & $\mathrm{~ns}$ \\
\hline Main effect & & & & \\
\hline Country & $0.25(0.2-0.3)$ & $1.7(1.2-2.7)$ & $0.8(0.6-1.0)$ & $1.1(0.9-1.4)$ \\
(reference: Sweden) & $\mathrm{p}<0.001$ & $\mathrm{p}=0.006$ & $\mathrm{p}=0.03$ & $\mathrm{~ns}$ \\
\hline Gender & $0.66(0.5-0.8)$ & $0.65(0.5-0.8)$ & $0.7(0.6-0.9)$ & $0.4(0.3-0.5)$ \\
(reference: female) & $\mathrm{p}<0.001$ & $\mathrm{p}=0.001$ & $\mathrm{p}=0.002$ & $\mathrm{p}<0.001$ \\
\hline Level of education & $0.8(0.6-1.0)$ & $1.0(0.8-1.2)$ & $1.1(0.7-1.4)$ & $1.8(1.4-2.2)$ \\
(reference: high education) & $\mathrm{p}=0.06$ & $\mathrm{~ns}$ & $\mathrm{~ns}$ & $\mathrm{p}<0.001$ \\
\hline
\end{tabular}


viour than Poles and more Swedes than Poles had successfully stopped smoking.

These results suggest that there is a greater discrepancy between health-related knowledge, attitude and behaviour among Poles than among Swedes. These results are consistent with previous observations suggesting that, in recent years, behavioural changes associated with cardiovascular risk behaviours in the Polish population have been relatively small (6). One possible interpretation of these findings is that, as a result of decades of health promotion, Swedes have reached a later stage in the process of behavioural change, while Poles are only at the beginning (2).

About $50 \%$ of the target population in Poland and $60 \%$ in Sweden took part in the initial health screening. Most of the participants who were invited and agreed to participate in the screening of risk factors completed the questionnaire. In the Polish sample, $98 \%$ of them answered the questions, while in Sweden about $90 \%$ of the participants who were involved in the survey did so.

One possible threat to the validity of the study may of course be that the non-participants may contribute to systematic biases, which may have created the statistical patterns described above. An earlier analysis of non-participants in the Swedish screening programme revealed that individuals with a low level of education, men and smokers were over-represented among non-participants, whereas no systematic differences between non-participants and participants were found for other variables relevant to this study (13). Although similar data for Poland are unavailable, these results suggest that the people who attend health screenings may be fairly representative of the population as a whole, in most of the respects relevant to this study. These results are consistent with earlier findings indicating that differences in social characteristics between participants and non-participants in CVD prevention programmes are marginal (15-17).

Another possible source of bias relates to the fact that the Polish data were collected some three years after the Swedish data. However, it should be noted that, since our data suggest that Poland is lagging behind Sweden, such a bias would work against rather than for the trends observed in our data.

This study suggests that knowledge, attitudes and behaviour consistency may vary widely between countries in the transition from Communist rule and countries from Western Europe, possibly as a result of these countries being at an early stage of a healthrelated behavioural change process.

A factor that may have further augmented the trends observed in the present study is possible differences in attitudes between inhabitants of post-Communist countries in Central and Eastern Europe and inhabitants of Western societies. It has been suggested that post-Communist citizens tend to be sceptical about institutions, thereby adopting a "wait and see" attitude (18).

These results imply that health promotion in the form of public mass media campaigns might benefit from focusing on the stage of the process of behavioural change in which most of the target population is to be found $(3,19)$. Information about risk factors that is directed at Swedes may therefore not be as effective as campaigns which focus on later stages of change. Another possible implication of our findings is that health interventions, which are tailor-made at individual level, may be more effective than undifferentiated media campaigns. One of the important lessons from the present study may be that, in countries with health systems in transition increasing knowledge of risk factors for the development of different diseases is not enough. Health workers may have to discuss the need for the introduction of relevant methods for behavioural change in more detail.

\section{REFERENCES}

1. Perlman F, Bobak M, Steptoe A, Rose R, Marmot M. Do health control beliefs predict behaviour in Russians? Prev Med. 2003 Aug;37(2):73-81.

2. Prochaska JO. Population treatment for addictions. Current Directions in Psychological Science. 2004 Dec;13(6):242-6.

3. Prochaska JO, DiClemente CC, Norcross JC. In search of how people change: applications to addictive behaviors. Am Psychol. 1992 Sep;47(9):1102-15.

4. Etter JF, Perneger TV, Ronchi A. Distributions of smokers by stage: international comparison and association with smoking prevalence. Prev Med. 1997 Jul-Aug;26(4):580-5.

5. Marmot M, Bobak M. International comparators and poverty and health in Europe. BMJ. 2000 Nov 4;321(7269):1124-8.

6. Zatonski WA, McMichael AJ, Powles JW. Ecological study of reasons for sharp decline in mortality from ischaemic heart disease in Poland since 1991. BMJ. 1998 Apr 4;316(7137):1047-51.

7. Weinehall L. Partnership for health: on the role of primary health care in a community intervention programme [medical dissertation]. Umeå: Umeå University; 1997.

8. Persson LG, Lindstrom K, Lingfors H, Bengtsson C. Results from an intervention programme dealing with cardiovascular risk factors. Experiences from a study of men aged 33-42 in Habo, Sweden. Scand J Prim Health Care. 1996 Sep;14(3):184-92.

9. Bjorkelund $\mathrm{C}$, Bengtsson C. Feasibility of a primary health care programme aiming at reducing cardiovascular and cerebrovascular risk factors among women in a Swedish community, Stromstad. Scand J Prim Health Care. 1991 Jun;9(2):89-95.

10. Rywik SL, Davis CE, Pajak A, Broda G, Folsom AR, Kawalec E, et al. Poland and U.S. collaborative study on cardiovascular epidemiology hypertension in the community: prevalence, awareness, treatment, and control of hypertension in the Pol-MONICA Project and the U.S. Atherosclerosis Risk in Communities Study. Ann Epidemiol. 1998 Jan;8(1):3-13.

11. Zdrojewski T, Pienkowski R, Szynkiewicz M, Krupa-Wojciechowska B. Have rapid socioeconomic changes influenced awareness of blood pressure in Poland? J Hum Hypertens. 2001 Apr;15(4):247-53.

12. Andersson P, Leppert J. Men of low socio-economic and educational level possess pronounced deficient knowledge about the risk factors related to coronary heart disease. J Cardiovasc Risk. 2001 Dec;8(6):371-7.

13. Risk factors in coronary heart diseases - regional and social disparity in Sweden. EpC Report 1997:1. Stockholm: Socialstyrelsen; 1997. (In Swedish.)

14. Osler MLJ, Rasmussen NK. A study of citizens' prevention of coronary heart diseases in Vejle. Report from Danish Institute for Clinical Epidemiology. Copenhagen: DICE; 1989. (In Danish.)

15. Weinehall L, Hallgren CG, Westman G, Janlert U, Wall S. Reduction of selection bias in primary prevention of cardiovascular disease through involvement of primary health care. Scand J Prim Health Care. 1998 Sep;16(3):171-6.

16. Tibblin G. A population study of 50-year-old men. An analysis of the non-participation group. Acta Med Scand. 1965 Oct;178(4):453-9.

17. Bostrom G, Hallqvist J, Haglund BJ, Romelsjo A, Svanstrom L, Diderichsen F. Socioeconomic differences in smoking in an urban Swedish population. The bias introduced by non-participation in a mailed questionnaire. Scand J Soc Med. 1993 Jun;21(2):77-82.

18. Mishler W, Rose R. Trust, distrust and skepticism: popular evaluations of civil and political institutions in post-communist societies. J Polit. 1997 May;59(2):418-51.

19. Prochaska JO, Velicer WF, DiClemente CC, Fava J. Measuring processes of change: applications to the cessation of smoking. J Consult Clin Psychol. 1988 Aug;56(4):520-8. 